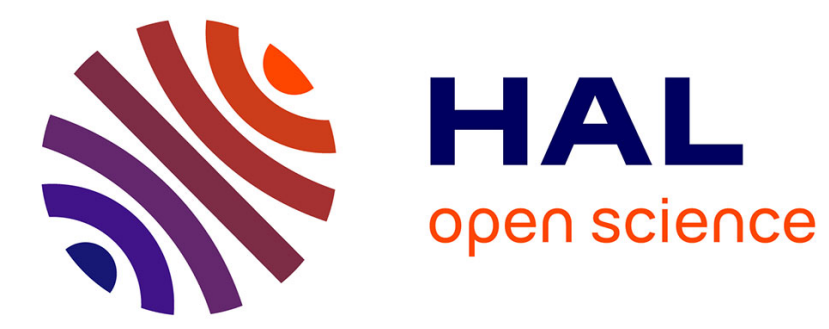

\title{
Airborne MIMO investigation for STAP-GMTI applications
}

\author{
Jean-François Nouvel, Frédéric Brigui, Hélène Oriot
}

\section{To cite this version:}

Jean-François Nouvel, Frédéric Brigui, Hélène Oriot. Airborne MIMO investigation for STAP-GMTI applications. RADAR 2019, Sep 2019, TOULON, France. hal-02417422

\section{HAL Id: hal-02417422 \\ https://hal.science/hal-02417422}

Submitted on 18 Dec 2019

HAL is a multi-disciplinary open access archive for the deposit and dissemination of scientific research documents, whether they are published or not. The documents may come from teaching and research institutions in France or abroad, or from public or private research centers.
L'archive ouverte pluridisciplinaire HAL, est destinée au dépôt et à la diffusion de documents scientifiques de niveau recherche, publiés ou non, émanant des établissements d'enseignement et de recherche français ou étrangers, des laboratoires publics ou privés. 


\section{Airborne MIMO investigation for STAP-GMTI applications}

\author{
Jean-François Nouvel \\ DEMR, ONERA \\ F-13661 Salon cedex Air - France \\ jnouvel@onera.fr
}

\author{
Frédéric Brigui, Hélène Oriot \\ DEMR, ONERA \\ F-91123 Palaiseau - France \\ fbrigui@onera.fr
}

\begin{abstract}
Ground moving target indicator (GMTI) radar performance is strongly depending on the antenna geometry: length of the equivalent radar aperture (longer apertures enable lower minimum detectable velocity - MDV) and sparsity. Compact and sparse multiple-input multiple-output (MIMO) techniques have been investigated into this paper to point out potential benefits compared to SIMO configuration. In 2016 an experiment was conducted with ONERA BUSARD motoglider to collect MIMO GMTI dataset on instrumented ground vehicles. DDMA waveform has been operated as orthogonal pattern on transmit. Analysis of the data indicates improved clutter nulling and resulting MDV with the MIMO techniques compared to the conventional SIMO one.
\end{abstract}

Keywords-MIMO, L band, STAP, BUSARD.

\section{INTRODUCTION}

SAR imagery techniques are in constant evolution. Today SAR sensors can provide high resolution images of the Earth surface regardless of sun illumination or weather conditions.

Some current evolutions are about resolution and coverage mitigation and scattering diversity and information optimization. MIMO technique is investigated to address these two topics for its potential benefits in beam-forming applications [1] and scene information extraction [2-3].

Conventional radar uses a single transmit channel and measures the backscattered signal with a single receive channel. First extension is about forming and using multiple phases centers on receive to perform as an example beamforming application. Such sensors are called SIMO for Single Input, Multiple Output. In a MIMO radar (for Multiple Input, Multiple Output) possibility has been added to transmit distinct waveforms on multiple transmit channels.

Both incoherent and coherent MIMO sensors are investigated in the literature. In the first case, sensor is based on broadly spaced antennas to achieve independent scattering responses across $\mathrm{Tx} / \mathrm{Rx}$ pairs. This kind of sensors allow for accessing scattering diversity from target. In the second case, sensor's antennas are close enough to allow combining coherently responses from target in order to improve angular resolution.

In this paper, we focus on a coherent airborne MIMO sensor to address STAP-GMTI applications [4]. Objective of MIMO configuration for airborne GMTI application is to improve location accuracy and reduce the minimum detectable velocity (MDV) compared to SIMO configuration.

Work has been based on airborne SIMO/MIMO antenna configurations operating at $\mathrm{L}$ band. This paper describes the process for defining radar parameters, the airborne system and measurements that have been collected and finally preliminary results from this campaign.

\section{RADAR PARAMETERS}

To fix radar parameters, a feasibility study has been done to determine theoretical performances as a function of the selected configuration. From mechanical constraints, antennas grazing angle was fixed to $10^{\circ}$.

The radar equation is well-known and we have to compare the two MIMO and SIMO contexts. We use the same approach as Kantor [5]. We remind that the Signal to Noise Ratio is given by the following relation where the parameters are described Table 1:

$$
S N R_{\text {SIMO }}=\left(\frac{S}{B}\right)_{\text {SIMO }}=\frac{\mathrm{P}_{\text {avg,SIMO }} \mathrm{Ge}_{\text {SIMOgr }} \lambda^{2} \sigma_{\text {Target }} \mathrm{T}_{\text {CPISIMO }}}{(4 \pi)^{3} d^{4} L K T_{0} F}
$$

In our context the difference between SIMO and MIMO radars is held in the three parameters $P_{a v g}, G_{e}$, and $T_{C P I}$, so $\mathrm{SNR}_{\text {SIMO }}$ is proportional to $\mathrm{P}_{\mathrm{avg}, \mathrm{SIMO}} \mathrm{G}_{\mathrm{e}, \mathrm{SIMO}} \mathrm{T}_{\mathrm{CPI}, \mathrm{SIMO}}$. This corresponds to an area rate which is inversely proportional to $\mathrm{G}_{\mathrm{e}, \mathrm{SIMO}} \mathrm{T}_{\mathrm{CPI}, \mathrm{SIMO}}$.

$$
\begin{array}{lllllll}
\text { SNR } & \text { SIMO } & \propto \mathrm{P}_{\text {avg, }} \text { SIMO } & \mathrm{Ge} & \text { SIMO } & \mathrm{T}_{\mathrm{CPI}}, \quad \text { SIMO } \\
\mathrm{AR} & \text { SIMO } & \propto \frac{1}{\mathrm{Ge}} \text { SIMO } & \mathrm{T}_{\mathrm{CPI}}, \quad \text { SIMO }
\end{array}
$$

Now if we consider a MIMO configuration, the main differences are related to:

- the transmit array which is partitioned into $\mathrm{N}_{\mathrm{e}}$ sub apertures. The two transmit antenna module parameters (gain, average power) decrease by the same factor $\mathrm{N}_{\mathrm{e}}$ :

$$
\frac{G e_{S I M O}}{N e} \text { and } \frac{P_{\text {avg }, S I M O}}{N e} \text {, }
$$

- the MIMO transmit beam is around $\mathrm{N}_{\mathrm{e}}$ times larger than the SIMO transmit beam. So during the same time, MIMO radar covers an area $\mathrm{N}_{\mathrm{e}}$ times broader.

So for MIMO radar, we have the relations:

$$
\begin{aligned}
& S N R_{\text {MIMO }} \propto \frac{\mathrm{P}_{\text {avg, SIMO }}}{N e} \mathrm{Ne}\left(\text { transmi } \quad \text { t) } \frac{\mathrm{Ge} \text { SIMO }}{N e} \mathrm{~T}_{\mathrm{CPI}, \text { MIMO }}\right. \\
& \mathrm{AR}_{\text {SIMO }} \propto \mathrm{Ne}\left(\text { cover } \quad \text { area) } \frac{1}{\frac{\mathrm{Ge} \text { SIMO }}{\mathrm{Ne}} \mathrm{T}_{\mathrm{CPI}, \text { MIMO }}}\right.
\end{aligned}
$$

To maintain the same performances for the two systems, we have, for MIMO radar, to increase the integration time to $\mathrm{N}_{\mathrm{e}} \mathrm{T}_{\mathrm{CPI}, \mathrm{SIMO}}$ :

$\mathrm{T}_{\text {CPIMIMO }}=\mathrm{N}_{\mathrm{e}} \mathrm{T}_{\text {CPISIMO }}$ 
TABLE I. RADAR EQUATION PARAMETERS

\begin{tabular}{|c|c|c|}
\hline \multicolumn{2}{|r|}{ Parameters } & Reference values \\
\hline $\begin{array}{l}\mathrm{SNR}= \\
\mathrm{S} / \mathrm{B}\end{array}$ & $\begin{array}{l}\text { Signal to noise to detect } \\
\text { a target versus a } \\
\text { detection probability and } \\
\text { a false-alarm probability }\end{array}$ & $13 \mathrm{~dB}(\min )$ \\
\hline $\mathrm{P}_{\mathrm{avg}}$ & $\begin{array}{l}\text { Transmit average power } \\
\mathrm{P}_{\mathrm{avg}}=\mathrm{DC} * \mathrm{P}_{\mathrm{c}} \\
\text { Pc : transmit peak power } \\
\mathrm{DC}: \text { maximum duty } \\
\text { factor allowed }\end{array}$ & $\begin{array}{c}\mathrm{P}_{\mathrm{c}}=15 \mathrm{~W} \text { for one } \\
\text { transmitter } \\
\mathrm{DC}=0.2 \\
\text { SIMO }: \mathrm{P}_{\text {avg,SIMO }}=12 \\
\mathrm{~W} \\
\text { MIMO }: \mathrm{P}_{\text {avg,MIMO }}=3 \\
\mathrm{~W}\end{array}$ \\
\hline $\mathrm{Ge}$ & Transmit antenna gain & $\begin{aligned} \text { SIMO }: & \text { Ge }=11.5 \\
& d B \\
\text { MIMO }: & g e=5.5 \mathrm{~dB}\end{aligned}$ \\
\hline $\mathrm{gr}$ & Receive antenna gain & $\mathrm{Gr}=5.5 \mathrm{~dB}$ \\
\hline$\sigma_{\text {target }}$ & $\begin{array}{l}\text { Target radar cross } \\
\text { section }\end{array}$ & $10 \mathrm{~m}^{2}$ \\
\hline $\mathrm{T}_{\mathrm{CPI}}$ & $\begin{array}{c}\text { Coherent Processing } \\
\text { Interval }\end{array}$ & To be defined \\
\hline $\mathrm{d}$ & $\begin{array}{c}\text { Range from target to } \\
\text { antenna }\end{array}$ & $6 \mathrm{~km}$ \\
\hline KT0 & $\begin{array}{c}\mathrm{K}=1.38 \times 10^{-23} \mathrm{~J} / \mathrm{K} \\
\text { Bolzmann's constant } \\
\mathrm{T} 0=290 \mathrm{~K} \text { nominal } \\
\text { scene noise temperature }\end{array}$ & $-204 \mathrm{~dB}$ \\
\hline $\mathrm{F}$ & Receiver noise figure & $4 \mathrm{~dB}$ \\
\hline $\mathrm{L}$ & Total losses & $8 \mathrm{~dB}$ \\
\hline
\end{tabular}

To perform a good detection of a target, a signal to noise ratio (SNR) of $13 \mathrm{~dB}$ minimum is generally considered. First we consider the radar equation in the SIMO configuration. From (1), $\mathrm{T}_{\mathrm{cpi}}=4.3 \mathrm{~ms}$. In MIMO configuration, this time is to be increased by a factor of $\mathrm{N}_{\mathrm{e}}$. For $\mathrm{N}_{\mathrm{e}}=4$, this coherent integration time is $17.2 \mathrm{~ms}$.

\section{WAVEFORM SELECTION}

If Space -Time Adaptive Processing (STAP) is wellknown to improve target detection and localization by airborne radar in presence of strong clutter (main lobe), MIMO STAP technique would offer increased performances by adding spatial degrees of freedom and extending the length of associated virtual arrays. One of the difficulties of such a technique is to sort and disentangle the different signals to differentiate the returned ones coming from each transmitter. A way to proceed is to use so-called "orthogonal" waveforms with good cross correlation properties. If such waveforms have a theoretical existence, this is not the case in practice, especially in our situation of extended clutter background, and the aim is to define quasi orthogonal waveforms.

Apart from the SIMO configuration (identical chirped waveform for each transmitter), we will basically rely on a "reference" MIMO waveform for data processing and performance assessment. Initially, three classical orthogonal waveforms have been considered: TDMA, FDMA and DDMA designs.

TDMA (Time Division Multiple Access): transmitters operate one after the other. The orthogonality is then achieved using time domain. But a major constraint of
TDMA waveforms is related to its usual mode of operation: successive transmissions reduce the average transmit power of the radar by a factor of $\mathrm{Ne}$. With $\mathrm{Ne}=4$, the loss is $6 \mathrm{~dB}$ in terms of SNR compared to "full" MIMO and this is not acceptable for the trials.

FDMA (Frequency Division Multiple Access): this type of waveform occupies different frequency bands at the same time (same pulse). The orthogonality is achieved using time domain by transmitting simultaneous signals with disjoint frequency bands at the same time. The full band from each transmitter is reconstructed from several consecutive pulses. The main drawback of FDMA waveforms is the loss of coherency caused by the disjoint frequency bands.

DDMA (Doppler Division Multiple Access): the signal of each transmitter integrates a specific Doppler modulation during the pulse train. Therefore, by construction, the signals returned by target and clutter to a receiver are Doppler separated. The orthogonality is achieved using slow time (Doppler domain) filtering.

This last waveform is simpler to operate compared to FDMA waveform and is more efficient in terms of effective PRF, with no energy loss. Then it has been selected to constitute the reference MIMO waveform for performance analysis on real dataset.

\section{AIRBORNE PAYLOAD AND MEASUREMENTS}

Three different antenna configurations have been investigated: SIMO, compact MIMO and sparse MIMO. Sparsity was performed on the transmit array while receive array remained fixed.

To compare the three of them, a dedicated BUSARD [6] payload has been designed (Fig. 1). The two antennas arrays are well visible on this picture. The Tx array is on top of the pod (in sparse configuration on Fig.1) and the Rx array is on the bottom part. Each of them is composed of $4 \mathrm{~L}$-band patch antennas.

Central frequency was fixed to $1200 \mathrm{MHz}$, with $40 \mathrm{MHz}$ instantaneous bandwidth. PRF was $8 \mathrm{kHz}$ and flight altitude and speed typically fixed to 4000 feet and $40 \mathrm{~m} / \mathrm{s}$ respectively.

Measurements were collected in the southern part of France, in the Salon de Provence area. Eight flights have been operated to collect a large dataset and allow comparisons between all modes.

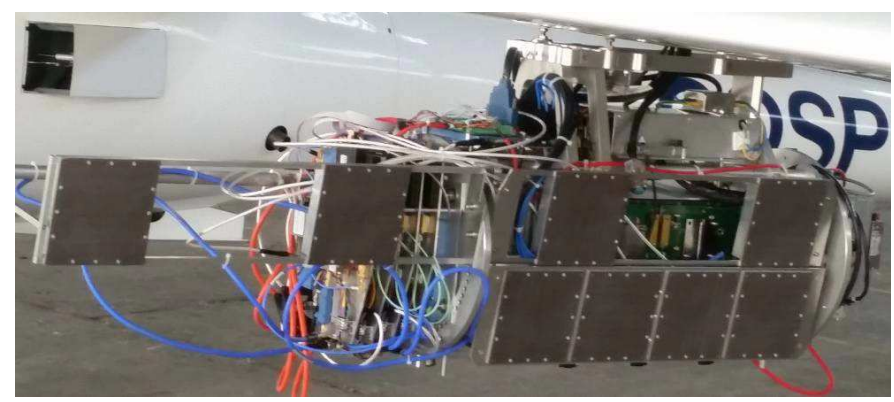

Fig. 1. MIMO payload on BUSARD. Sparse MIMO configuration. Airborne covers are removed. 


\section{PRELIMINAR RESULTS}

In this paragraph, we present for each mode a SAR image (spotlight mode) from the dataset, and a range/Doppler map respectively. With these figures, we first checked that the beampattern is consistent with each operated mode.

In SIMO mode, a single virtual Tx channel is formed by coherent addition of the four physical Tx ones. There is no grating lobe (Figure 2) and Range/Doppler map is showing the resulting single Tx antenna beam (Figure 3).

\section{SIMO configuration:}

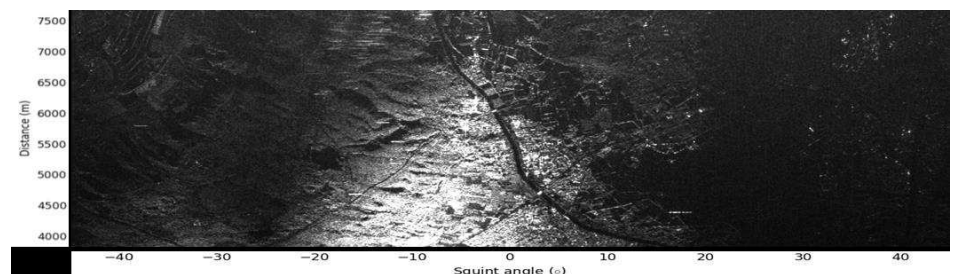

Fig. 2. SAR image from SIMO dataset. Spotlight processing.

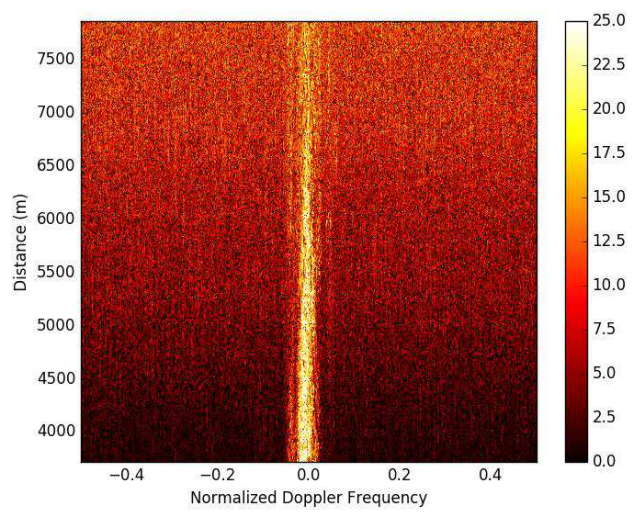

Fig. 3. Range/Doppler map from SIMO dataset.

In MIMO configurations, the four physical $\mathrm{Tx}$ channels are used. In compact mode, there is no grating lobe lobe (Figure 4) and due to DDMA process, Range/Doppler mal is showing the resulting four Tx antenna beams shifted in Doppler (Figure 5).

In sparse mode, some grating lobes appear (Figure 6) and Range/Doppler map is showing here again the resulting four Tx antenna beams (Figure 7).

MIMO COMPACT configuration:

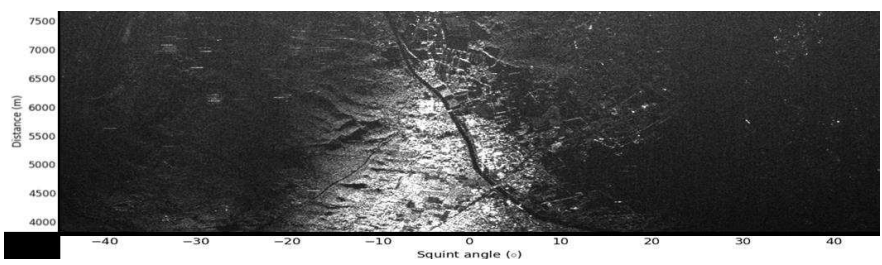

Fig. 4. SAR image from MIMO compact dataset. Spotlight processing.

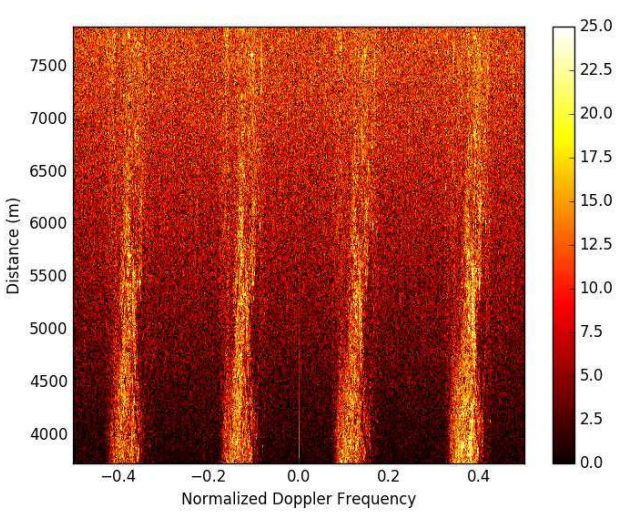

Fig. 5. Range/Doppler map from MIMO compact dataset.

MIMO SPARSE configuration:

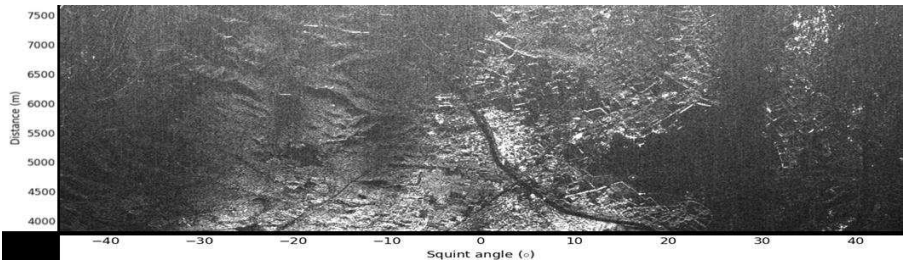

Fig. 6. SAR image from MIMO sparse dataset. Spotlight processing.

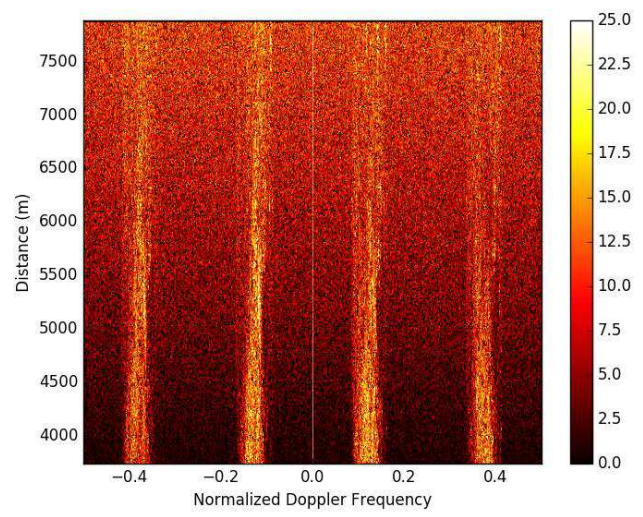

Fig. 7. Range/Doppler map from MIMO sparse dataset.

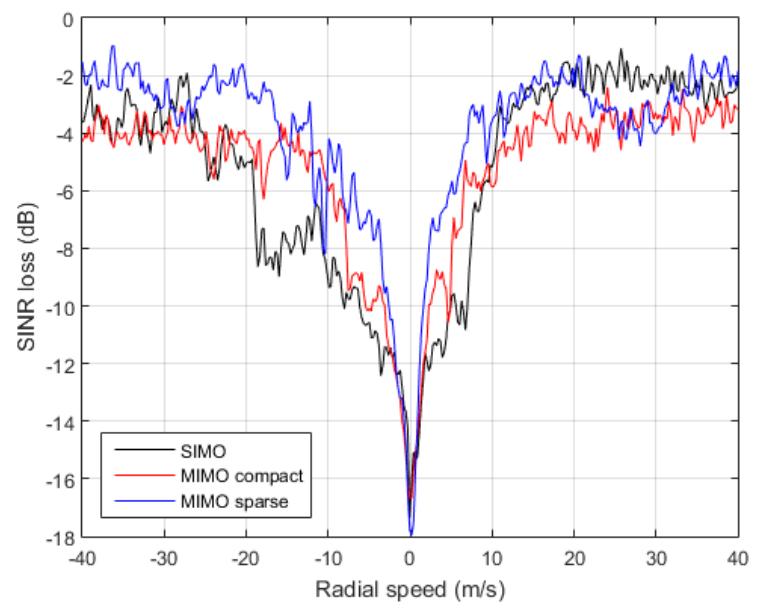

Fig. 8. Comparison of SINR losses between all modes. 


\section{CONCLUSIONS}

Airborne SAR acquisition campaign dedicated to MIMO sparse, MIMO compact and SIMO performances characterization has been performed.

A large number of measurements runs have been done, leading to the acquisition of a radar dataset that covers different geometries and configurations: vehicles relative headings, vehicles velocity, airborne configurations: SIMO, MIMO compact and MIMO sparse modes have been investigated.

We checked out that MIMO sparse mode allows narrower mainbeam compared to MIMO compact and SIMO modes but induces greater sidelobes.

Figure 8 present comparisons of SINR loss between SIMO, MIMO compact and MIMO sparse. Clutter nulling is clearly narrower for MIMO sparse compared to MIMO compact and SIMO. In clutter region, SINR loss for MIMO sparse is lower than around $5 \mathrm{~dB}$ compared to MIMO compact and $7 \mathrm{~dB}$ compared to SIMO.

This large database is still under investigation, and data processing is on-going.
Authors thank all ONERA team that participated to the data collection campaign and the data processing.

\section{REFERENCES}

[1] Krieger G., Younis M., Huber, S., Bordoni, F., Patyuchenko A., Kim J., Laskowski P., Villano M., Rommel T., Lopez P., Moreira A.; "Digital Beamforming and MIMO SAR: Review and New Concepts", Proceedings of EUSAR 2012.

[2] Forsythe K. W. and Bliss D. W., "MIMO radar: Concepts, performance enhancements, and applications," in MIMO Radar Signal Processing, J. Li and P. Stoica, Eds. New York: Wiley, 2009.

[3] Rabideau D. J., "Adaptive MIMO radar waveforms," Proceedings of the IEEE Radar Conference, pp. 1-6, 2008.

[4] Ward J., "Space-time adaptive processing for airborne radar," MIT Lincoln Laboratory, Tech. Rep. TR-1015, Dec. 1994.

[5] Kantor J. and Davis S.; "Airborne GMTI Using MIMO Techniques", Proceedings of the IEEE Radar Conference, pp. 1344-1349, 2010.

[6] Nouvel J.F., Roques S., Ruault du Plessis O.; « A low cost imaging radar: DRIVE on board ONERA motoglider», Proceedings of IGARSS 2007.

\section{ACKNOWLEDGMENT}

